\title{
Oropharyngeal Basaloid Carcinoma
}

National Cancer Institute

\section{Source}

National Cancer Institute. Oropharyngeal Basaloid Carcinoma. NCI Thesaurus. Code C126751.

A high-grade variant of squamous cell carcinoma that arises from the oropharynx. It is characterized by the presence of small malignant cells with hyperchromatic nuclei and scant amount of cytoplasm forming lobules with peripheral palisading. 